\title{
Recessive aplasia cutis congenita of the limbs*
}

\author{
N FREIRE-MAIA, M PINHEIRO, AND C C ORTEGA \\ From the Department of Genetics, Federal University of Paraná, Curitiba; and The Medical School, \\ Itajubá, Brazil
}

SUMMARY Six inbred persons (five males and one female) in three generations of a single family are reported as having simple congenital absence of skin on the upper or lower limbs or both. The data suggest an autosomal recessive pattern of inheritance for this apparently new clinical entity.

Aplasia cutis congenita (ACC) is a clinically and aetiologically heterogeneous group of conditions usually involving the scalp (over $80 \%$ of cases) as well as the lower limbs, trunk, neck, upper limbs, and face (with or without scalp involvement). A number of other congenital anomalies have been reported in association with ACC: absence of ear lobes ${ }^{1}$; congenital heart disease ${ }^{2}$; cleft lip and palate, anophthalmos, and deformed ears ${ }^{3}$; and neurological changes. ${ }^{4}$ ACC may also be seen in the $4 p$ - syndrome, the 13 trisomy syndrome, Johanson-Blizzard syndrome, focal dermal hypoplasia (also known as Goltz-Gorlin syndrome, an ectodermal dysplasia of the tricho-odonto-onycho-dyshidrotic subgroup), acrocephalopolysyndactyly, and a syndrome of reduction deformities of the limbs and aplasia of the skull and scalp. ${ }^{56}$ For reviews and case reports, see also Abt, ${ }^{7}$ Adair and Stewart, $^{8}$ Dowler, ${ }^{9}$ Rauschkolb and Enriquez, ${ }^{10}$ Sirol et al, ${ }^{11}$ Bart, ${ }^{12}$ and Fisher and Schneider. ${ }^{13}$

This paper describes and discusses the occurrence of congenital absence of skin in the upper or lower limbs or both in six members (five males and one female) of three inbred sibships of the same kindred.

\section{Case reports}

The pedigree (fig 1) comprises seven generations of 238 Caucasians (six with ACC) from the northeastern Brazilian state of Ceará. Three males, not personally examined, (VI.8, VI.17, and VI.20) from a consanguineous marriage $(F=3 / 64)$ were reported as having had ACC only in the lower limbs. One (VI.8) had the right foot (dorsum, sole, and toes) affected, and two (VI.17 and VI.20) had both legs and

*This study was supported by grants from the National Council for Scientific and Technological Development (Brazil) and the World Health Organization.

Received for publication 31 May 1979 feet (dorsum, sole, and toes) affected. ACC in the upper and lower limbs (dorsum of the hands, and dorsum of the feet and toes) was reported in IV.14, an inbred man $(F=1 / 8)$ who died at the age of 30 years.

The following is a description of two cases, the only ones we were able to examine.

\section{CASE VII. 4 (INDEX CASE)}

A 5-year-old female from a consanguineous marriage $(F=1 / 27)$ had ACC in the right leg and foot (fig 2). Labour was normal and the baby was otherwise normal. The treatment consisted of covering the red areas with vitamin $\mathbf{A}$; sterile gauze dressings were applied to avoid trauma and infection. A few months after birth the lesions healed completely and spontaneously (fig 2 ). The clinical appearance of the defect is now similar to the hypotrichotic scar of an old burn.

CASE VI. 7

This case was an adult when the diagnosis of ACC was made. A 34-year-old male from a consanguineous marriage $(F=3 / 64)$ had a scarred area on the dorsum of his right hand (fig 3 ). No treatment was given, but precautions to avoid trauma and infection were taken by his parents.

\section{Discussion}

Intrauterine disturbances and genetic factors have been considered in the aetiology of ACC (reviews by Rogatz and Davidson, ${ }^{1}$ Farmer and Maxmen, ${ }^{3}$ Mardini et al, ${ }^{6}$ Dowler, ${ }^{9}$ Montgomery ${ }^{14}$ ). The 'scalp' form is reported as having an autosomal dominant pattern of inheritance. ${ }^{2101315}$ Isolated cases of 'different' forms of ACC have also been reported, at least one of them being the offspring of a consanguineous mating. ${ }^{37891116-18}$ These isolated 


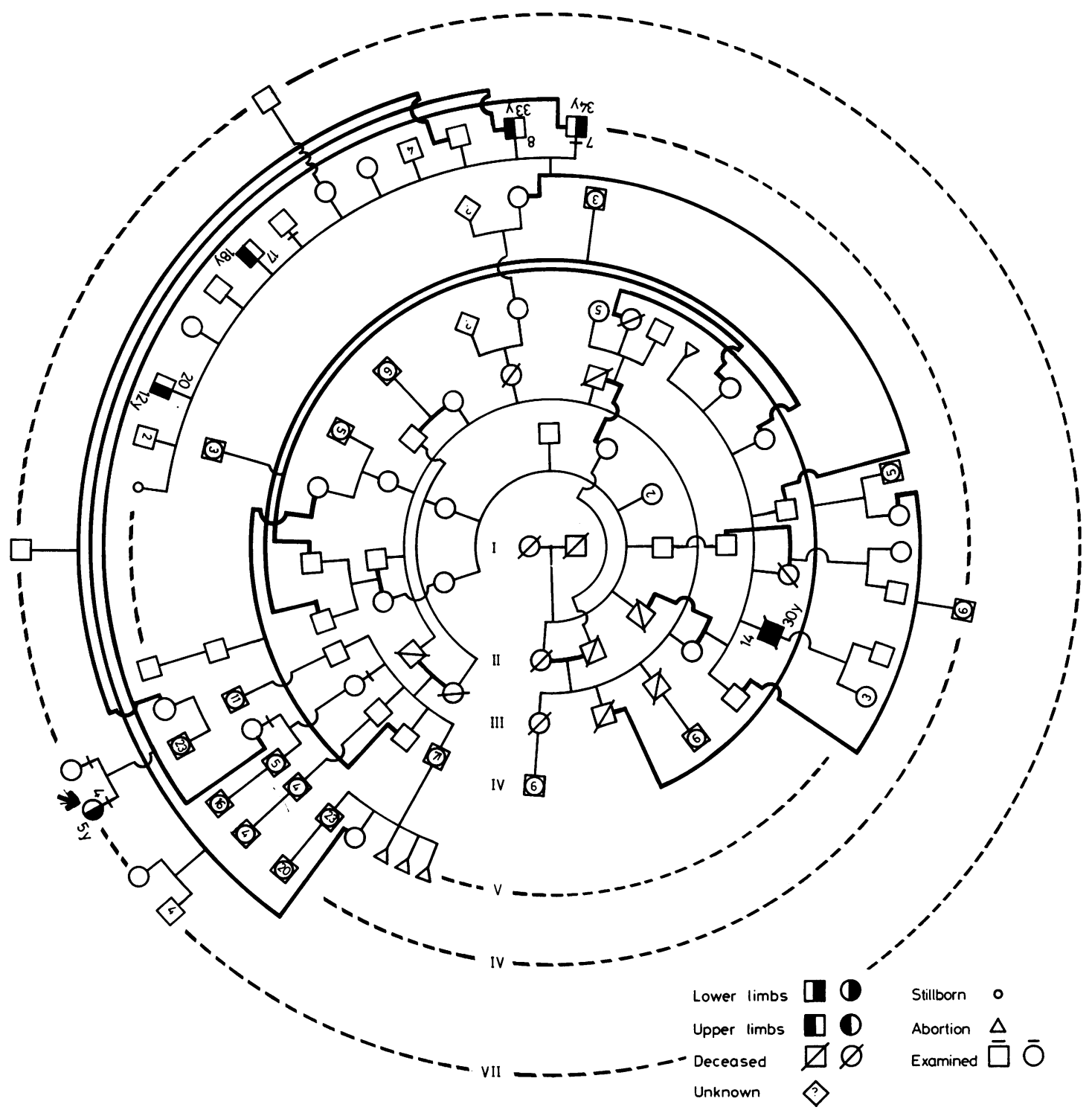

FIG 1 Pedigree of family.

cases involved (1) the scalp with or without bone defect; (2) the scalp and the trunk; (3) the scalp and congenital malformations not related to the skin; (4) the trunk and the upper limbs; (5) the knees only; and (6) the lower limbs only.

Our data show that (1) all affected persons are inbred; (2) the father of one of them, who married a relative, is also affected; (3) the segregation ratio among the children of normal parents is $5 / 22$, and among the children of the affected father is $1 / 2$; (4) there are five males and one female among the affected. These facts indicate an autosomal recessive pattern of inheritance.

This condition is not listed in McKusick's catalogue. ${ }^{5}$ The condition referred to by Rauschkolb and Enriquez ${ }^{10}$ in item 20770 of this catalogue is also characterised by skin aplasia of the limbs, but, as mentioned before, is the result of a dominant gene with incomplete penetrance. Gedda et $a l,{ }^{19}$ also cited in that item, reported 'cases of aseptic gangrene of 

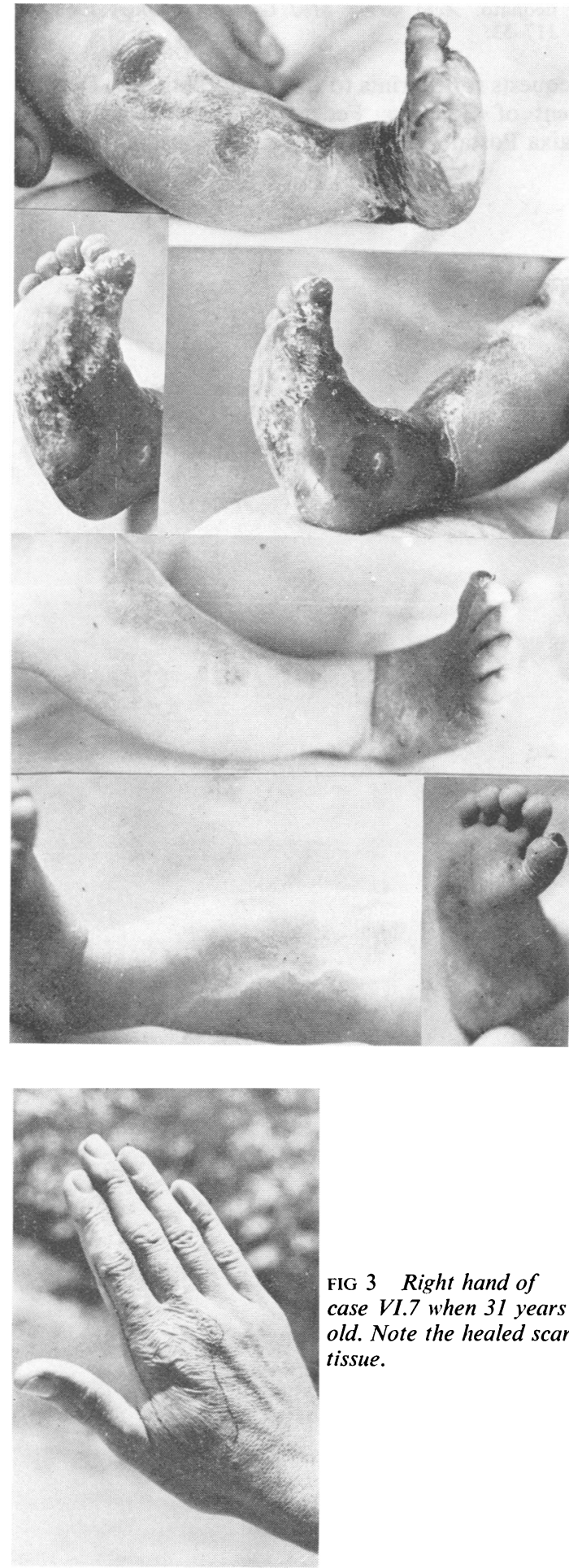

FIG 2 Right leg and foot of index case VII.4. Upper photos: at birth, defect covered by glistening, translucent membrane. Lower photos: cicatrisation after a few months.

the skull', also called 'localised skull aplasia'. This again has nothing to do with the condition seen in our patients who had normal skulls.

The form of ACC we describe, involving regions of both upper and lower limbs (without scalp and trunk involvement), seems to be a 'new' condition with an unquestionable autosomal recessive pattern of inheritance.

We are very grateful to Dr Rita Maria Patribu Faria for her collaboration during the treatment of the index case.

\section{References}

1 Rogatz JL, Davidson HB. Congenital defect of the skin in a newborn infant. Am J Dis Child 1943;65:916-9.

2 Deeken JH, Caplan RM. Aplasia cutis congenita. Arch Dermatol 1970;102:386-9.

3 Farmer AW, Maxmen MD. Congenital absence of skin. Plast Reconstr Surg 1960;25:291-7.

4 Ruiz-Maldonado R, Tamayo L. Aplasia cutis congenita, spastic paralysis, and mental retardation. Am J Dis Child 1974;128:699-701.

5 McKusick VA. In: Mendelian inheritance in man. 4th ed. Baltimore: Johns Hopkins University Press, 1975.

6 Mardini MK, Ghandour M, Sakati NA, Nyhan WL. Johanson-Blizzard syndrome in a large inbred kindred with three involved members. Clin Genet 1978;14:247-50.

7 Abt AA. Congenital skin defects. Am J Dis Child 1917; 14:113-21.

8 Adair FL, Stewart CA. Congenital defect of the skin of the new-born. Am J Dis Child 1923;27:60-3.

9 Dowler VB. Congenital defect of the skin in a new-born infant. Am J Dis Child 1932;44:1279-84.

10 Rauschkolb RR, Enriquez SI. Aplasia cutis congenita. Arch Dermatol 1962;86:102-5.

11 Sirol J, Revil H, Sagnet H, Thomas J, Mafart Y. Les aplasies cutanées congénitales. Med Trop 1967;27:175-82.
FIG 3 Right hand of case VI.7 when 31 years old. Note the healed scar tissue. Birth defects atlas and compendium. Baltimore: Williams and Wilkins, 1973:582.

13 Fisher M, Schneider R. Aplasia cutis congenita in three successive generations. Arch Dermatol 1973;108:252-3.

14 Montgomery H. In: Dermatopathology. vol I. New York: Paul B Hoeber, 1967.

15 Cutlip CBD Jr, Cryan CDM, Vineyard WR. Congenital scalp defects in mother and child. Am J Dis Child 1967; 113:597-9.

16 Ollivier D, Janvier H. A propos des agénésies cutanées congénitales. Ann Chir Plast 1969;14:39-44. 
17 Croce EJ, Purohit RC, Janovski NA. Congenital absence of skin. Arch Surg 1973;106:732-4.

18 Rilke F, Riviera LC. Aplasia cutis congenita: descrizione di un caso in prodotto incestuoso. Folia Hered Pathol 1964;14:35-48.

19 Gedda L, Muratore A, Bernardi A. La gangrena asettica della teca cranica come aplasia oircoscritta ereditaria del neonato. Acta Genet Med Gemellol (Roma) 1963;12: 117-33.

Requests for reprints to Dr Marta Pinheiro, Department of Genetics, Federal University of Paraná, Caixa Postal AA, 80000 Curitiba, Paraná, Brazil. 